\title{
Distributing development assistance for health: simulating the implications of 11 criteria
}

\author{
TRYGVE OTTERSEN* \\ Department of Global Public Health and Primary Care, University of Bergen, Bergen, Norway \\ Department of International Public Health, Norwegian Institute of Public Health, Oslo, Norway \\ Oslo Group on Global Health Policy, Department of Community Medicine and Global Health, Centre for Global \\ Health, University of Oslo, Oslo, Norway \\ SUERIE MOON \\ Harvard T.H. Chan School of Public Health, Harvard University, Boston, MA, USA \\ JOHN-ARNE RØTTINGEN \\ Harvard T.H. Chan School of Public Health, Harvard University, Boston, MA, USA \\ Department of Health Management and Health Economics, University of Oslo, Oslo, Norway \\ Infectious Disease Control and Environmental Health, Norwegian Institute of Public Health, Oslo, Norway
}

\begin{abstract}
After years of unprecedented growth in development assistance for health $(\mathrm{DAH})$, the DAH system is challenged on several fronts: by the economic downturn and stagnation of DAH, by the epidemiological transition and increase in non-communicable diseases and by the economic transition and rise of the middle-income countries. Central to any potent response is a fair and effective allocation of DAH across countries. A myriad of criteria has been proposed or is currently used, but there have been no comprehensive assessment of their distributional implications. We simulated the implications of 11 quantitative allocation criteria across countries and country categories. We found that the distributions varied profoundly. The group of low-income countries received most DAH from needs-based criteria linked to domestic capacity, while the group of upper-middle-income countries was most favoured by an income-inequality criterion. Compared to a baseline distribution guided by gross national income per capita, low-income countries received less DAH by almost all criteria. The findings can inform funders when examining and revising the criteria they use, and provide input to the broader debate about what criteria should be used.
\end{abstract}

*Correspondence to: Trygve Ottersen, Department of Global Public Health and Primary Care, University of Bergen, PO Box 7804, 5020 Bergen, Norway. Email: trygve.ottersen@medisin.uio.no 


\section{Introduction}

\section{Transitions and challenges}

The past two decades have witnessed an unprecedented growth in development assistance for health (DAH). Disbursements by bilateral, multilateral and other donors increased from \$7 billion in 1990 to \$34 billion in 2010 (2015 \$US) (Institute for Health Metrics and Evaluation [IHME], 2016). Now, however, the DAH system is challenged on several fronts. The economies of many traditional and emerging funders of DAH are struggling, and while funders can choose to still prioritise DAH (Stuckler et al., 2011), there has only been tepid growth in DAH over the last five years (IHME, 2016). Another challenge is the epidemiological transition and the triple burden of disease that many countries are facing today (Frenk et al., 2011; Frenk and Moon, 2013). New opportunities but also new challenges, for the DAH system are also emerging with the economic transition and the rise of middle-income countries (MICs). The MIC category now comprises 105 countries (fiscal year 2015), 70\% of the world's population, over $30 \%$ of the global gross domestic product, over $75 \%$ of the world's poor, and almost $70 \%$ of the disease burden in the world (Sumner, 2012) (based on data from the World Bank and the Institute for Health Metrics and Evaluation).

Central to any potent response to this situation is a fair and effective allocation of DAH across countries. The fundamental question is what allocation criteria should be utilised by the funders in this evolving and increasingly complex landscape. This is unsettled. A myriad of criteria is currently employed, by funders such as Gavi, the Vaccine Alliance (Gavi) and the Global Fund to Fight AIDS, Tuberculosis and Malaria (Global Fund), or has been proposed (Ottersen et al., 2017). In particular, gross national income per capita (GNIpc) is widely used to guide allocations of aid today, and one key question is what role GNIpc should play.

Many studies have examined what factors - including country characteristics that de facto correlate with the allocation of aid across countries and country categories (Alesina and Dollar, 2000; Neumayer, 2003; Berthelemy, 2006; Dieleman et al., 2014). However, surprisingly few studies have examined the potential distributional implications of a wide range of aid allocation criteria, including the consequences for countries and country categories of using various criteria to a greater extent than today (Llavador and Roemer, 2001; Collier and Dollar, 2002; McGillivray, 2004; Guillaumont, 2008; Guillaumont et al., 2015). Moreover, no study, to our knowledge, has done this in the specific context of health and the distribution of DAH, although recent work for the Equitable Access Initiative has examined how the classification of countries may change with different criteria (Global Fund, 2016).

\section{Objective}

The objective of this study was to examine the potential distributional implications of 11 quantitative allocation criteria for DAH across countries and country categories. 
A basic understanding of the implications of different candidate criteria is important for several reasons. For funders of DAH, it is helpful to have insight in these implications when they assess or revise the criteria they use. This is the case even if many other considerations also influence funders' choice of allocation criteria and actual allocations. Especially for bilateral funders, historical, political and traderelated considerations are likely to influence what criteria are used and what decisions are made (Berthelemy, 2006; Vázquez, 2015). An understanding of the implications of different candidate criteria is also important for other stakeholders and the broader community when debating how DAH should be allocated across countries. A good understanding of allocation criteria is also central to the many new global financing mechanisms that have been proposed (Ooms et al., 2006; Consultative Expert Working Group, 2012; Moon and Omole, 2013; Gostin, 2014).

The remainder of this section discusses allocation criteria in general, while the third section describes the specific criteria examined and the simulation procedure used to derive distributional implications. The fourth section presents these implications, the fifth section discusses the findings, and the final section concludes.

\section{Allocation criteria}

Allocation criteria, of the kind addressed here, guide the allocation of DAH across recipient countries. Every funder of DAH uses some allocation criteria, but they are not necessarily explicit and they may go by another names. Most eligibility criteria, for example, can be seen as one kind of allocation criteria that apply early in the allocation process and that is linked to a necessary condition for receiving any funding.

Explicit criteria generally have a number of advantages (Daniels and Sabin, 2008). Compared with implicit ones, explicit criteria tend to better facilitate transparency, accountability and public deliberation. These effects are valuable in themselves, but they are also likely to promote the development of better criteria. Moreover, explicit and especially quantitative criteria may improve the consistency of funding decisions, increase predictability and support the coordination of DAH allocations and contributions. Quantitative criteria are particularly apt for being explicit and for generating these benefits.

Explicit, quantitative allocation criteria are currently not as widely used as they could be, and the criteria stated by major funders of DAH vary considerably (Ottersen et al., 2017). Amidst the multitude of allocation criteria used or proposed, there are also commonalities. Two overarching criteria pervade the allocation schemes used by major funders of DAH: criteria related to need and criteria related to effectiveness (Ottersen et al., 2017). While terminology varies considerably, many specific criteria can be usefully subordinated to one of these.

According to need criteria, aid is to be allocated to countries with the greater need. Need is often understood to decrease with the current or projected level of development or some other outcome of interest (Anderson, 2008; 
Guillaumont, 2008; Leo, 2010; Basu et al., 2014; Crosswell, 2015). Candidate indicators include, for example, GNIpc, the Human Development Index (HDI), life expectancy at birth, under-five mortality rate (U5MR) and burden of disease. Need for assistance can also be understood in terms of the country's capacity to address domestic challenges and further develop without external assistance (Anderson, 2008; Guillaumont, 2008; Leo, 2010; Crosswell, 2015; Resch et al., 2015). Need criteria can overlap significantly with equity criteria (Guillaumont, 2008).

According to effectiveness criteria, aid is to be allocated to countries where it will be more effective. Effectiveness can be defined as increasing with the health gain, such as a reduction in U5MR, or some other desired outcome from the intervention in question (Anderson, 2008; Guillaumont, 2008; Pietschmann, 2014; Cagé, 2015; Crosswell, 2015). If one consider the effectiveness of a given amount of DAH, effectiveness overlaps with common understandings of costeffectiveness and efficiency. 'Effectiveness' can also overlap with 'expected impact', 'performance' and 'absorptive capacity' in several different ways, depending on the terminology used. Specific effectiveness criteria rarely refer directly to the ultimate outcome of interest, partly because the information needed is not readily available. Instead, effectiveness criteria typically refer to an indicator of expected effectiveness which may pertain to demonstrated improvements in the past or to a country characteristic perceived to correlate with the effectiveness of aid (Anderson, 2008; Guillaumont, 2008; Pietschmann, 2014; Cagé, 2015; Crosswell, 2015). The former may include past reduction in U5MR or past improvement in vaccine coverage, and the latter may include high institutional quality and low level of corruption.

Need criteria should be complemented with effectiveness criteria because assistance to those most in need is not necessarily the most effective use of available resources and is sometimes very ineffective. Conversely, effectiveness criteria will typically be insufficient alone because most of us not only care about the sum total of benefits, but also how badly off the people who receive the benefits are. The two overarching criteria can also relate in various ways and interact with several other criteria, including criteria involving conditionality (Ottersen et al., 2017).

\section{Methods}

We simulated the implications of 11 quantitative allocation criteria across countries and country categories.

\section{Criteria}

Multiple criteria are currently guiding the allocation of DAH, and many others have been proposed. For any assessment, discussion or choice of criteria, it is crucial to understand how the basic candidate criteria influence the 
distribution of DAH. Even if no criterion is sufficient alone, the distributional implications of single criteria indicate how each of those criteria affects the overall distribution if part of a set. Examination of single criteria is thus also a useful first step to examining packages of criteria.

Against this background, we examined 11 criteria. The selection of criteria was based on a review of indicators and criteria currently used by major funders and criteria proposed in the literature (Anderson, 2008; Guillaumont, 2008; Ottersen et al., 2017). We specifically sought to include criteria that related to different kinds of needs, to effectiveness, or to inequality. Similarly, the operationalisation of each of criteria examined was motivated by allocation criteria currently used or previously proposed, but the criteria were streamlined and simplified to facilitate comparison and intuitive understanding.

The nature of each criterion is best appreciated if it is seen as a combination of a metric and a prioritisation rule. The metric is the country characteristic that the criterion is directly concerned with, for example, level of GNIpc. The prioritisation rule specifies how the amount of DAH changes when a country's value of a given metric increases. Key properties of the criteria are summarised in Table 1.

\section{Criteria related to need}

We examined six needs-based criteria. Three of these are linked to health outcomes. According to the U5MR criterion, DAH increases with U5MR. This is a key indicator of severe deprivation in health, and it is part of the allocation formula used by United Nations Children's Fund (UNICEF) (Ottersen et al., 2017). According to the life expectancy (LE) criterion, DAH decreases with life expectancy at birth. Life expectancy is an indicator of health deprivation that is sensitive to mortality in both children and adults, but not directly sensitive to morbidity. Life expectancy is part of the HDI, which is used by the Luxembourg Agency for Development Cooperation to determine country eligibility for aid (Ottersen et al., 2017). According to the disability-adjusted life year rate (DALYr) criterion, DAH increases with DALYr, which is the number of DALYs per 100,000 individuals. DALYr is an indicator of health deprivation in terms of length of life as well as quality of life. The Global Fund is among the funders that use disease burden to guide their decisions on country eligibility and allocation of DAH (Ottersen et al., 2017).

The three remaining needs-based criteria are primarily linked to countries' capacity to address health needs. According to the GNIpc criterion, DAH decreases with GNIpc. This is an indicator widely used determine countries' eligibility for aid and how much aid they are to be offered (Ottersen et al., 2017). In the context of DAH, GNIpc is particularly relevant as an indicator of domestic capacity to address health needs.

According to the criterion linked to government health expenditure per capita (GHEpc), DAH decreases with GHEpc. This is an indicator of the short-term 
Table 1. Properties of the examined criteria

\begin{tabular}{|c|c|c|c|c|c|}
\hline Name of metric and criterion & Abbreviation & $\begin{array}{l}\text { Prioritisation rule } \\
\text { (effect on DAH) }\end{array}$ & Weighting & Data year & Data source \\
\hline \multicolumn{6}{|l|}{ Needs-related criteria } \\
\hline Under-five mortality rate (per 1000 live births) & U5MR & + & Yes & 2011 & World Bank \\
\hline Life expectancy (years) & $\mathrm{LE}$ & - & Yes & 2011 & World Bank \\
\hline Disability-adjusted life year rate (per 100,000 individuals) & DALYr & + & Yes & 2010 & IHME \\
\hline Gross national income per capita (\$US) & GNIpc & - & Yes & 2011 & World Bank \\
\hline Government health expenditure per capita (\$US) & GHEpc & - & Yes & 2011 & World Bank \\
\hline Government health expenditure gap from $\$ 86$ (\$US) & GHEpc gap & + & Yes & 2011 & World Bank \\
\hline Conditional government health expenditure gap from $\$ 86$ (US) & $5 \%$ gap & + & Yes & 2011 & World Bank \\
\hline \multicolumn{6}{|l|}{ Effectiveness-related criteria } \\
\hline International Development Association Resource Allocation Index & IRAI & + & No & 2011 & World Bank \\
\hline Reduction in under-five mortality rate (per 1000 live births) & cU5MR & + & No & 2005-2011 & World Bank \\
\hline \multicolumn{6}{|l|}{ Other } \\
\hline Gini index & Gini & + & Yes & $2005-2012$ & World Bank \\
\hline Inequality in life expectancy & LEi & + & Yes & 2011 & UNDP \\
\hline
\end{tabular}

Note: IHME = Institute for Health Metrics and Evaluation. UNDP = United Nations Development Programme.

Missing data: GNIpc: countries for which data for years other than 2011 used were Djibouti (2009), Iran (2012), Libya (2009) and Syria (2010). Sufficiently recent estimates were unavailable for Myanmar, North Korea and Somalia. LE: estimates were unavailable for Dominica and Marshall Islands. DALYr: estimate was unavailable for South Sudan. GHEpc: estimates were unavailable for North Korea, occupied Palestinian Territory, Somalia and Zimbabwe. GHEpc gap: estimates were unavailable for North Korea, occupied Palestinian Territory, Somalia and Zimbabwe. 5\% gap: countries for which data for years other than 2011 were used were Djibouti (2009), Iran (2012), Libya (2009) and Syria (2010). Sufficiently recent estimates were unavailable for Myanmar, North Korea and Somalia. IRAI: for Azerbaijan, the value for 2010 was used. The estimate for Sudan was also used for South Sudan. Estimates were unavailable for 59 countries. Gini: for 64 countries, estimates for years between 2005 and 2012 other than 2011 were used. The 2009 estimate for Sudan was also used for South Sudan. Suffciently recent estimates were unavailable for 35 countries. LEi: for Kiribati, Seychelles, South Sudan and Sudan estimates for 2013 were used. Estimates for Dominica and Marshall Islands were unavailable. 
capacity to ensure priority services for the entire population. ${ }^{1}$ According to criterion linked to GHEpc gap from $\$ 86$, DAH increases with the shortfall of GHEpc from $\$ 86$. This gap is supposed to indicate the lack of resources for ensuring priority services for everyone in the context of low-income countries (LICs). The reference level of $\$ 86$ (in both 2012 and 2015 terms) is a recently updated figure of the estimate for total health expenditure per capita of the Task Force for Innovative International Financing for Health Systems (McIntyre et al., 2017). In this study, however, $\$ 86$ was taken to represent the minimum level of GHEpc, because it was believed that for $\$ 86$ to ensure priority services to everyone, it needs to come from mandatory, prepaid, pooled funds rather than from private spending. According to the criterion linked to conditional GHEpc gap from $\$ 86$ (5\% gap), DAH increases with the shortfall of GHEpc from $\$ 86$ that would exist if GHE in the country represented $5 \%$ of GNI. A GHE/GNI ${ }^{2}$ ratio of at least $5 \%$ has been suggested as a useful target for government health expenditure (McIntyre et al., 2017). The 5\% gap can be seen as a indication of the lack of capacity to meet health needs, since any such gap suggests that countries are unable to reach the $\$ 86$ target even if they spent $5 \%$ of GNI on publicly financed health services. It has been suggested that the primary role of DAH is to reduce this gap (Røttingen et al., 2014).

For most need-based criteria, rank-dependent weights were applied (see Table 1). This was done by first ranking all countries from best off to worst off in terms of the indicator in question. The worst-off country was assigned a weight of two and the best-off country a weight of one. The weights assigned to each country in between decreased proportionally with its rank. This adjustment was made in order to incorporate the widespread belief that the worse off should have some special priority and to do so in a simple manner that retained an intuitive grasp of how the criteria work.

\section{Criteria related to effectiveness}

We examined two criteria related to effectiveness. According to the criterion linked to the International Development Association (IDA) Resource Allocation Index (IRAI), DAH increases with the IRAI. This measure is developed by the IDA and based on the Country Policy and Institutional Assessment (CPIA), which evaluates performance in terms of the quality of country's policy and institutional framework (International Development Association, 2013). As many believe good governance improves the effectiveness of aid, IRAI is typically seen as an indicator of expected aid effectiveness.

According to the criterion linked to reduction in U5MR (rU5MR), DAH increases with recent reduction in U5MR. Reduction in U5MR can be seen as an indicator of demonstrated effectiveness and possibly an indicator of expected aid effectiveness.

1 Although GHEpc can be seen as an indicator of domestic capacity, part of GHE in many LICs and MICs derives from external assistance.

2 We do not distinguish between GNI and gross domestic product (GDP) here. 


\section{Other criteria}

We examined three criteria that does not clearly fall into the need or effectiveness categories, although inequality measures are often linked to need. According to the Gini index (Gini) criterion, DAH increases with the Gini index for income. A high value indicates greater inequality and more specifically that many people fall below the average level of income, that some people fall far below that average, or some combination. Income inequality is relevant for DAH primarily due to the correlation between income and health and due to the fact that low income can make health services unaffordable.

According to the criterion linked to inequality in life expectancy (LEi), DAH increases with LEi. This criterion is relevant for mainly the same reasons as the Gini criterion, but refers more directly to inequalities in health.

\section{Countries and country categories}

Our initial sample of countries included all low- and middle-income countries (LMICs) that received DAH in $2011(n=138)$ (Institute for Health Metrics and Evaluation [IHME], 2014). In the presentation of results, we concentrate on five focus countries for illustrative purposes: Ethiopia, India, Ghana, Nigeria and South Africa. The five countries were chosen with aim of creating a diverse set of countries well suited for highlighting the distributional implications of different allocation criteria. Table 2 exhibits key characteristics of these countries, including several of the indicators examined in this study. As shown, the countries vary in multiple dimensions, including in population size, national income (GNIpc), health spending (GHEpc), health outcomes (U5MR and LE), improvement in health outcomes (cU5MR), inequality (Gini), and DAH received in 2011.

Table 2. Characteristics of focus countries

\begin{tabular}{|c|c|c|c|c|c|c|c|c|c|c|}
\hline Countries & $\begin{array}{c}\text { Population } \\
\text { (million) }\end{array}$ & $\begin{array}{c}\text { Income } \\
\text { class }\end{array}$ & $\begin{array}{c}\text { GNIpc } \\
\text { (\$US) }\end{array}$ & $\begin{array}{l}\text { GHEpc } \\
\text { (\$US) }\end{array}$ & $\begin{array}{l}\text { U5MR } \\
\text { (per } \\
1000)\end{array}$ & $\begin{array}{c}\mathrm{LE} \\
\text { (years) }\end{array}$ & $\begin{array}{c}\text { cU5MR } \\
\text { (per } \\
1000)\end{array}$ & $\begin{array}{l}\text { Gini } \\
\text { index }\end{array}$ & $\begin{array}{c}\text { DAH } \\
\text { (million } \\
\text { \$US) }\end{array}$ & $\begin{array}{c}\text { DAHpc } \\
\text { (\$US) }\end{array}$ \\
\hline Ethiopia & 89 & LIC & 390 & 7 & 71 & 62 & 38 & 34 & 816 & 10 \\
\hline Nigeria & 164 & LMIC & 1710 & 29 & 126 & 52 & 33 & 43 & 757 & 5 \\
\hline Ghana & 25 & LMIC & 1420 & 46 & 82 & 61 & 7 & 43 & 224 & 9 \\
\hline India & 1221 & LMIC & 1450 & 19 & 58 & 66 & 17 & 34 & 933 & 1 \\
\hline South Africa & 52 & UMIC & 6850 & 319 & 48 & 55 & 32 & 65 & 666 & 13 \\
\hline
\end{tabular}

Note: GNIpc = gross national income per capita; GHEpc = government health expenditure per capita; $\mathrm{U} 5 \mathrm{MR}=$ under-five mortality rate; $\mathrm{LE}=$ life expectancy; cU5MR = reduction in under-five mortality rate; $\mathrm{DAH}=$ development assistance for health; DAHpc $=\mathrm{DAH}$ per capita; LIC = low-income country; LMIC = low- and middle-income country; UMIC = upper-middle-income country.

Data sources: data on DAH and DAHpc from Institute for Health Metrics and Evaluation and for 2011. Other data from World Bank and for 2011. World Bank income class for fiscal year 2015. 
Implications for four categories of countries were also examined. Three of these were World Bank income classes for the fiscal year 2015 (Word Bank, 2015). According to this classification, countries with GNIpc $\leq \$ 1045$ in 2013 are classified as LICs; countries with GNIpc \$1046-\$4125 and \$4126-\$12 745 as LMICs and upper-middle-income countries (UMICs), respectively; and countries with GNIpc $\geq \$ 12,746$ as high-income countries. The fourth category examined comprised the $20 \%$ of countries with the lowest life expectancy. Implications across income classes were examined because much of the debate on the allocation of DAH and aid more generally is framed in terms of the role of MICs compared with that of LICs. Similarly, implications for the countries with the lowest life expectancy were studied because concerns for countries with profound health needs also figure prominently in the current debate.

\section{Simulation procedure}

For each criterion, the question was the following: how will the total amount of DAH currently available be distributed across countries and country categories if only this criterion is applied? For each criterion, we also examined how the distribution differed from an income baseline, that is the distribution based on a GNIpc criterion alone. Given the prominent role of GNIpc in the allocation of aid (Ottersen et al., 2017), it is useful to directly compare the shares of DAH resulting from each criterion with the distribution that follows from a GNIpc criterion alone.

Obviously, no single funder or other actor is in position to determine the allocation criteria for all DAH worldwide. Funders also have different goals and mandates. However, examining how different criteria would allocate the total amount helps demonstrate how these criteria can affect the overall distribution of DAH, and this can inform funders' choice of criteria. The overall distribution of $\mathrm{DAH}$ is also relevant for debates in the wider global community, where broad patterns of DAH are discussed.

The model used to simulate distributions relied heavily on proportional relationships in order to facilitate an intuitive understanding of the criteria and their implications. The scales of the 11 indicators were normalised so that the lowest and highest observed value for every indicator were 1 and 10, respectively. For criteria according to which DAH increases with the metric, the following procedure was used. We posited that DAH for a given country $i\left(D_{i}\right)$ increases proportionally with DAH per capita (DAHpc) $\left(d_{i}\right)$ and population size $s_{i}$. We further assumed that $d_{i}$ increases proportionally with a constant $a$ that applied for every country, the rank-dependent weight for the country $\left(w_{i}\right)$, and the level of the metric for the country $\left(m_{i}\right)$.

$$
D_{i}=d_{i} s_{i}=a w_{i} m_{i} s_{i}
$$

We imposed the constraint that the sum of DAH across all countries $n$ must equal total DAH currently available. This was defined as the total amount of 
DAH in 2011 that could be attributed to specific countries (IHME, 2014). That total was $\$ 14,582,799,981$.

$$
\sum_{i}^{N} D_{i}=\sum_{i}^{N} a w_{i} m_{i} s_{i}=a \sum_{i}^{N} w_{i} m_{i} s_{i}=14,582,799,981 \text { \$US }
$$

We solved (2) for each criterion to find $a$. With $a$ identified, we calculated the distribution of DAH, that is the amount of DAH allocated to each country $i$, by using (1).

For criteria according to which DAH decreases with the metric, such as the GNIpc criterion, $m_{i}$ in (1) and (2) was replaced by $m_{i}^{-1}$. When the estimate for $m_{i}$ for a given indicator and given country was unavailable, DAH actually received in 2011 was used to calculate $a$ and overall DAH for country categories.

\section{Results}

\section{Shares of assistance}

Figure 1 shows for each criterion the share of total DAH going to each focus country. The leftmost bar exhibits the countries' actual share of DAH in 2011. Supplementary Appendix 1 provides findings for all countries.

This figure demonstrates substantial variation in how the criteria allocate DAH across the five countries. For example, Ethiopia's share varied from $1 \%$ (Gini) to $10 \%$ (5\% gap). This represents a difference of $>\$ 1.4$ billion, which is almost double the amount that Ethiopia currently receives. The greatest variation, however, was seen for India, whose share varied from 12\% (Gini) to $39 \%$ (GHEpc gap). Through comparison with the leftmost bar, Figure 1 also illustrates

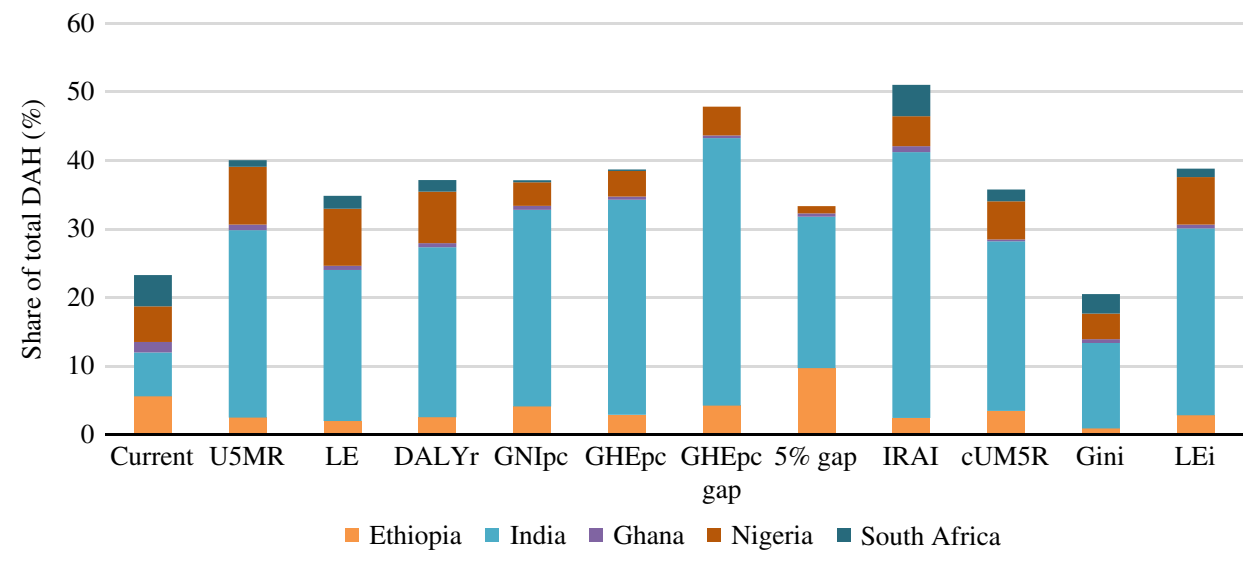

Figure 1. Allocations across focus countries by different criteria (share of total development assistance for health [DAH])

Note: abbreviations and data sources: see Table 1 


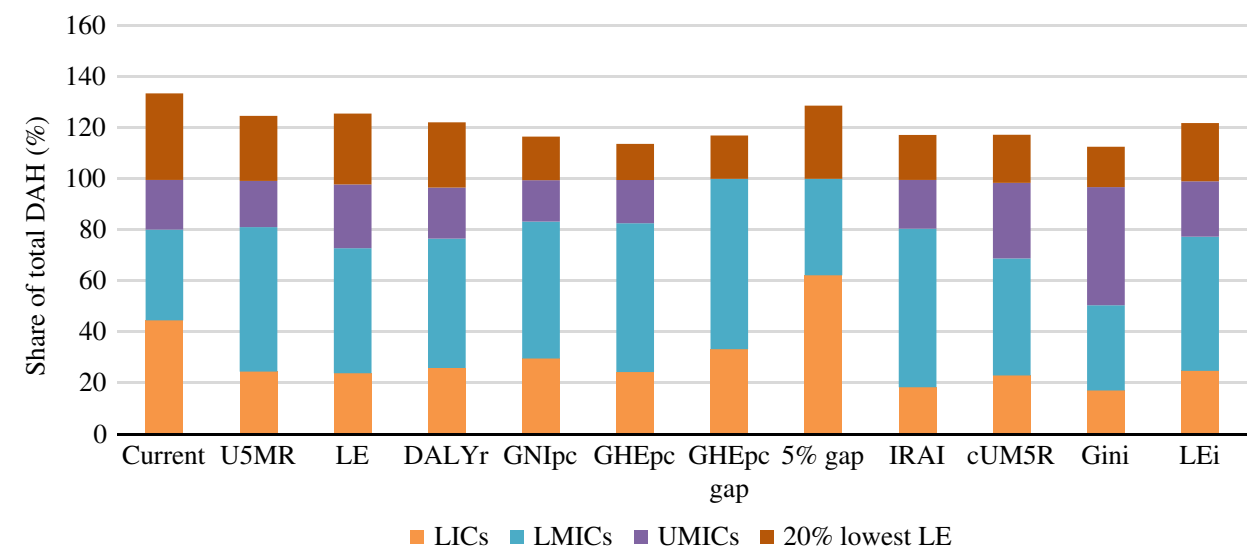

Figure 2. Allocations across country categories by different criteria (share of total development assistance for health [DAH])

Note: abbreviations and data sources: see Table 1

the differences between the allocations following each of the criteria and the actual allocations in 2011. Again, allocations to India stand out most clearly as India is consistently allocated more than double the amount it receives today. This is likely to be mainly explained by the assumption of proportionality with respect to population size in the simulation procedure.

With regard to country categories, Figure 2 shows for each criterion the share of total DAH to each category. The sum of shares for the LICs, LMICs and UMICs is $100 \%$ since these categories are mutually exclusive and only countries in these income classes were included in the sample.

This figure demonstrates substantial variation also across country categories, with several clear patterns. LICs as a group was most favoured by needs-based criteria linked to capacity (GNIpc, GHEpc gap, and 5\% gap), while the UMIC group was clearly most favoured by the Gini criterion. The $20 \%$ of countries with the lowest life expectancy was most favoured by needs-based criteria linked to health outcomes (U5MR, LE and DALYr) and to the $5 \%$ gap. Compared with the current distribution (leftmost bar), the LMICs appear to benefit most consistently from the use of the examined criteria. This is again likely to be partly explained by the assumption of proportionality with respect to population size in the simulation procedure and the fact that many LMICs have large populations.

\section{Difference from income baseline}

Given the prominent role of GNIpc in today's allocation of aid, it is useful to directly compare the shares of DAH following from each of the other criteria with the distribution that follows from a GNIpc criterion alone. In contrast to a baseline based on today's distribution of DAH, the comparison with such a GNIpc baseline is less sensitive to assumption about proportionality with respect to 


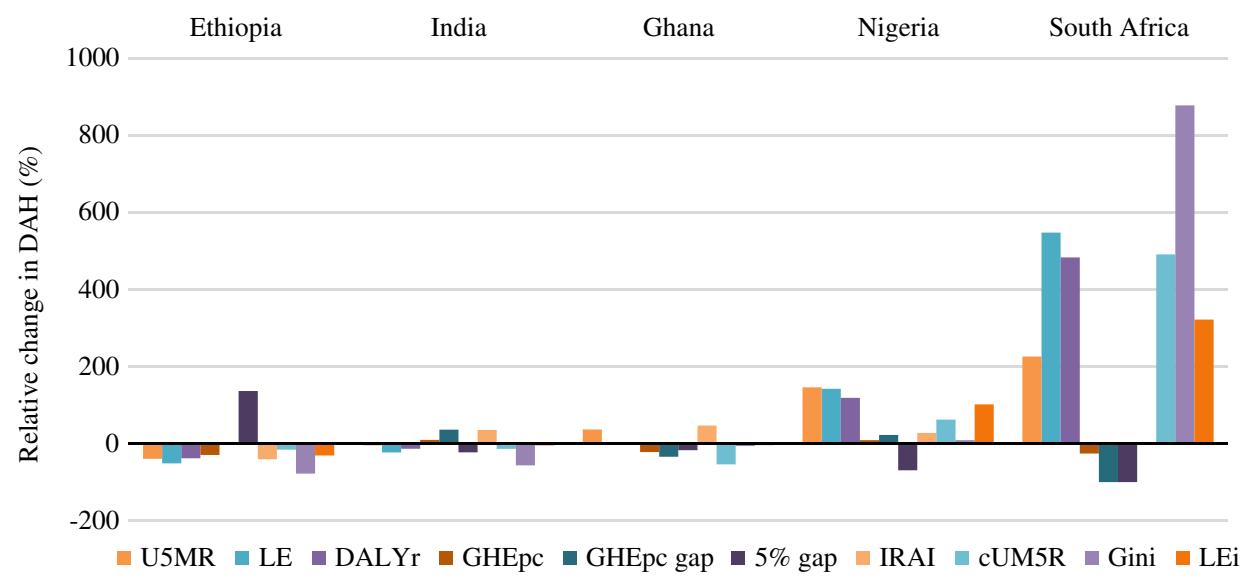

Figure 3. Allocations across focus countries by different criteria (relative difference from income baseline)

Note: abbreviations and data sources: see Table 1

population size in the simulation procedure. Figure 3 exhibits the relative differences for each focus country, and Supplementary Appendix 2 provides findings for all countries.

This figure demonstrates marked deviations from a distribution based on the GNIpc criterion alone. The greatest changes are seen for South Africa, which experienced a pronounced increase in DAH from any move from the GNIpc criterion towards the criteria linked to health outcomes (U5MR, LE and DALYr), recent health improvements (cUM5R), or inequality (Gini and LEi), with the Gini criterion as the most favourable. However, South Africa was disadvantaged by any move from the GNIp criterion to the other capacity-related criteria (GHEpc, GHEpc gap and 5\% gap).

The other focus countries also experienced substantial changes, and there were several clear patterns. Ethiopia received less DAH by any move from the GNIpc criterion, except by a move towards the criteria linked to the GHEpc gap or the $5 \%$ gap. Conversely, Nigeria benefited from any move from the GNIpc criterion to another criterion, except the 5\%-gap criterion. For India and Ghana, the picture was more mixed.

With regard to country categories, Figure 4 shows the change in allocations when moving from a GNIpc criterion to each of the other criteria.

The figures shows that there were substantial changes also for country categories. The most pronounced shifts were seen for the UMICs, with a pattern quite similar to that seen for South Africa (an UMIC). Specifically, the UMIC group benefited profoundly from a move from the GNIpc criterion to the Gini criterion and to a lesser extent also to any other criterion, except the needs criteria linked to capacity (GHEpc, GHEpc gap and 5\% gap). Conversely, LICs as a group 


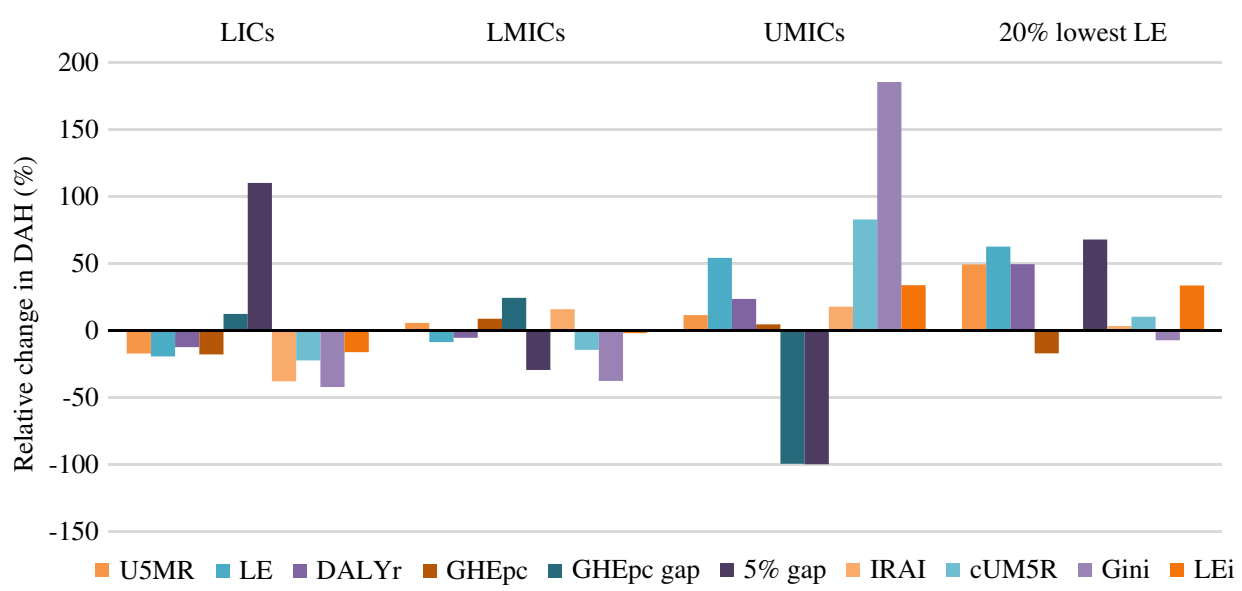

Figure 4. Allocations across country categories by different criteria (relative difference from income baseline)

Note: abbreviations and data sources: see Table 1

was consistently disadvantaged by a move away from the GNIpc criterion, only with the exception of the criteria linked to the GHEpc gap and the 5\% gap. This pattern is similar to that seen for Ethiopia (a LIC).

The $20 \%$ countries with the lowest life expectancy received more DAH as a group when one moved from the GNIpc criterion to criteria linked to health outcomes, the $5 \%$ gap, or LEi. For LMICs the picture was more mixed.

\section{Discussion}

The findings show that the distribution of DAH across countries and country categories vary substantially among different criteria. Although not surprising, this demonstrates that countries' various characteristics are not aligned in a way that makes all plausible criteria favour the same countries, and that the choice of criteria matters. The findings also demonstrate that the criteria examined in this study are likely to affect the relationship between LICs and MICs, which is a key topic in the ongoing debate on the allocation of DAH.

More specifically, the findings suggest that LICs may receive most DAH from needs-based criteria linked to capacity, and especially criteria such as the $5 \%$ gap criterion. UMICs, on the other hand, may benefit the most from criteria linked to inequality, such as the Gini criterion. Compared with a distribution guided by GNIpc, LICs may be disadvantaged by the move to most other criteria. Implications for LMICs appear more diverse.

The overview of distributional implications does not provide direct recommendations to funders about what criteria they should use. Instead, it provides a basis for funders to themselves consider their current criteria and possibly revise 
the criteria they use. This includes both bilateral funders and multilateral funders such as Gavi and the Global Fund.

In addition to providing general input to the assessment and revision of criteria, the findings specifically shed light on issues related to health needs, inequalities and population size and the cross-cutting issue about the proper role of MICs (Ottersen et al., 2017).

\section{Health needs}

To meet health needs is widely seen as a central purpose of DAH. Many have therefore argued for supplementing GNIpc criteria with criteria directly linked to health needs in the country. The findings of this study indicate what would be the implications of applying any of the three health-needs criteria (U5MR, LE and DALYr). Specifically, the findings suggest that LICs may receive less DAH if funders supplement their GNIpc criterion with a health-needs criterion, compared with using GNIpc alone. These findings may also serve as a useful reminder for those who push for new criteria to supplement GNIpc in the allocation of DAH. The findings call for any such push to be accompanied by an examination of the consequences for LICs. The stagnation of DAH in recent years only underscores the importance of a careful examination of this kind.

\section{Inequalities}

Persisting or increasing inequalities in income or health pose a challenge to the current practices of allocating DAH. Even for countries with an adequate average level of income or health, pronounced inequalities suggest that parts of the population experience severe poverty, poor health or both. It may thus be tempting to use inequality as a metric of need, where DAH increases with the level of inequality. The findings of this study indicate what the implications of such a strategy could be. Specifically, the findings suggests that inequality-based criteria, and criteria based on Gini in particular, may markedly favour UMICs.

Irrespective of the distribution across country categories, inequality criteria risk being damaging on incentives (Basu et al., 2014). If greater inequalities implies more DAH, countries have less incentive to reduce these. It has also been argued that greater inequality may indicate higher capacity to address needs (Ceriani and Verme, 2013). If so, one may hold that the relation between inequality and DAH should be the opposite, ie. that DAH should decrease with inequality. Whatever criteria are used, there is also a question about to what extent one should bypass the government in face of persisting inequalities.

\section{Population size}

The role of population size often remains in the periphery of discussions on the allocation of DAH. The findings of this study indicates that how one deals with 
population size can have a huge impact on allocation. In the simulations, highly populous countries, such as India, tended to receive much more DAH than they do today. This is likely to have been driven in large part by the assumption about proportionality with respect to population size in the simulation procedure. The underlying rationale for such an assumption is that needy individuals have an equal claim on assistance, irrespective of whether they happen to be part of a small or large population.

However, proportionality with respect to population size seems to be far from today's de facto allocation of aid. It has been suggested that per capita development assistance tend to decrease with population size or increase and then decrease (Alesina and Dollar, 2000; Neumayer, 2003; Salois, 2012). This may be explained by perceptions about the correlation between population size and other factors, such as economies of scale, resilience to shocks and effectiveness. However, there is reason to question whether today's approach is well-founded and consistent, especially with regard to health needs. While some studies have simulated the implications of different approaches to population size (Guillaumont, 2008; Guillaumont et al., 2015), its proper role in the allocation of DAH deserves more systematic scrutiny.

\section{Wider considerations}

To promote a fair and effective overall distribution of DAH is likely to be only one among several considerations that funders make. As mentioned above, historical ties and political and trade-related interests will often play a key role. These factors may lead funders to make decisions that go against their own stated criteria, but the same factors may also influence the choice of criteria in the first place. Irrespective of their fundamental aims, funders may also want to consider the quality and availability of indicators when choosing their allocation criteria, and they may want to consider the risk for gaming or false reporting. It is also important, of course, that the criteria align with other policies. For example, the criteria for allocation across countries may need to be adjusted to fit the desired criteria for allocation across disease areas.

\section{Limitations and future inquiry}

Although this study examined eleven criteria, there are many other plausible candidates, and the various criteria may be operationalised in ways different from what was done here. This study also examined only single criteria. Future studies may consider other criteria and examine the implications of packages of criteria, building on insights on the implications of individual criteria. These studies could also pay more attention to effectiveness criteria and to how GNIpc and income class relate to the effectiveness of DAH (Glennie, 2011; Thomas, 2013). 
The simulation involved a number of methodological choices, and many of these could reasonably be made differently. One example is the choice of normalisation, which may have considerable impact (McGillivray, 2004; Guillaumont, 2008; Guillaumont et al., 2015). In addition, the operationalisation of the criteria and the specification of the weights, including the weight capturing the concern for the worse off, could have been based on empirically derived preferences. This would have been interesting although the relevance for the question about how DAH should be allocated is not straightforward. Another general issue is that none of the examined criteria was forward looking in that they included future projections. Finally, none of the criteria was directly based on a health production function or a costing or budget methodology (Fan et al., 2014).

Future research can address the issues highlighted by this study in greater depth, including the role of health needs, inequalities, and population size in the allocation of DAH. In particular, it would be useful to examine how major funders of DAH deal with population size - implicitly or explicitly - and what approaches that could be justified by economies of scale and other widely accepted concerns. Since populous countries, including China and India, heavily influence the distribution across country categories, it would also be useful to characterise their role with more precision than have been done here. This would also allow for more useful comparisons between distributional implications from specific criteria and today's pattern of DAH.

Finally, this study has considered criteria for the allocation of DAH among eligible countries. It is important to also examine the implications of different criteria determining eligibility for DAH and transitioning from DAH (Glassman et al., 2013; Salvado and Walz, 2013). Although the same metric - such as GNIpc - often is used for these different kinds of criteria, the consequences can be very different.

\section{Conclusion}

With large unmet needs and limited funds available, a fair and effective allocation of DAH is essential. In this study, we simulated distributional implications across countries and country categories for 11 allocation criteria. We found that the distributions varied profoundly. The group of LICs received most DAH from needs-based criteria linked to domestic capacity, while the group of UMICs was most favoured by the income-inequality criterion. Compared with a baseline distribution guided by GNIpc, LICs received less DAH from almost all criteria. The findings can inform funders when examining and revising the criteria they do use, and provide input to the broader debate about what criteria should be used.

\section{Acknowledgements}

The authors are grateful to the members of the Working Group on Health Financing at Chatham House Centre on Global Health Security and to Joseph Dieleman, Victoria Fan and Martin McKee for their valuable comments. 


\section{Supplementary material}

To view supplementary material for this article, please visit https://doi.org/ $10.1017 /$ S1744133116000487

\section{References}

Alesina, A. and D. Dollar (2000), 'Who gives foreign aid to whom and why?', Journal of Economic Growth, 5: 33-63.

Anderson, E. (2008), 'Practices and implications of aid allocation', Background Study for the 2008 Development Cooperation Forum. UN Economic and Social Council (ECOSOC). http://www.un.org/en/ecosoc/newfunct/pdf/revised\%20draft(anderson).pdf

Basu, S., D. Stuckler and M. McKee (2014), 'An alternative mechanism for international health aid: evaluating a global social protection fund', Health Policy and Planning, 29: 127-136.

Berthelemy, J.-C. (2006), 'Bilateral donors' interest vs. recipients' development motives in aid allocation: do all donors behave the same?', Review of Development Economics, 10(2): 179-194.

Cagé, J. (2015), 'Improving upon the World Bank's Country Policy and Institutional Assessment: a new performance indicator based on aid effectiveness', Journal of Globalization and Development, 5(2): 213-233.

Ceriani, L. and P. Verme (2013), 'The Income Lever and the Allocation of Aid', ECINE Working Paper Series, Society for the Study of Economic Inequality, Verona, Italy.

Collier, P. and D. Dollar (2002), 'Aid allocation and poverty reduction', European Economic Review, 46: 1475-1500.

Consultative Expert Working Group (2012), 'Research and Development to Meet Health Needs in Developing Countries: Strengthening Global Financing and Coordination', CEWG on Research and Development: Financing and Coordination. Geneva: World Health Organization.

Crosswell, M. (2015), 'Country Selectivity and Extreme Poverty', USAID Economics Brief, USAID, Washington, DC.

Daniels, N. and J. E. Sabin (2008), Setting Limits Fairly: Learning to Share Resources for Health, 2nd edn, New York: Oxford University Press.

Dieleman, J. L., C. M. Graves, T. Templin, E. Johnson, R. Baral, K. Leach-Kemon, A. M. Haakenstad and C. J. L. Murray. (2014), 'Global health development assistance remained steady in 2013 but did not align with recipients' disease burden', Health Affairs, 33(5): 878-886.

Fan, V. Y., A. Glassman and R. L. Silverman (2014), 'How a new funding model will shift allocations from the Global Fund to Fight AIDS, tuberculosis, and malaria', Health Affairs, 33(12): 2238-2246.

Frenk, J., O. Gómez-Dantés and F. Chacón (2011), 'Global Health in Transition', in R. Parker and M. Sommer (eds), Routledge Handbook in Global Public Health, New York: Routledge.

Frenk, J. and S. Moon (2013), 'Governance challenges in global health', New England Journal of Medicine, 368: 936-942.

Glassman, A., D. Duran and A. Sumner (2013), 'Global health and the new bottom billion: what do shifts in global poverty and disease burden mean for donor agencies?', Global Policy, 4(1): 1-14. 
Glennie, J. (2011), 'The Role of Aid to Middle-Income Countries: A Contribution to Evolving EU Development Policy', Working Paper 331, Overseas Development Institute, London.

Global Fund (2016), 'Equitable Access Initiative', Global Fund to Fight AIDS, Tuberculosis and Malaria, http://www.theglobalfund.org/en/equitableaccessinitiative/ [25 September 2016].

Gostin, L. O. (2014), Global Health Law, Cambridge, MA: Harvard University Press.

Guillaumont, P. (2008), 'Adapting Aid Allocation Criteria to Development Goals', Essay for the 2008 Development Cooperation Forum, Clermont-Ferrand, France.

Guillaumont, P., S. G. Jeanneney and L. Wagner (2015), 'How to Take Into Account Vulnerability in Aid Allocation Criteria and Lack of Human Capital as Well: Improving the Performance Based Allocation', FERDi Working Paper, Fondation pour les Etudes et Recherches sur le Développement International, Clermont-Ferrand, France.

Institute for Health Metrics and Evaluation (IHME) (2014), Financing Global Health 2013: Transition in an Age of Austerity, Seattle, WA: IHME.

Institute for Health Metrics and Evaluation (IHME) (2016), Financing Global Health 2015: Development Assistance Steady on the Path to New Global Goals, Seattle, WA: IHME.

International Development Association (2013), 'Annex 2. IDA's performance-based allocation system for IDA17’, IDA, http://www.worldbank.org/ida/papers/Annex_2_IDA17.pdf [28 Feburary 2015].

Leo, B. (2010), 'Inside the World Bank's Black Box Allocation System: How Well Does IDA Allocate Resources to the Neediest and Most Vulnerable Countries?', Working Paper 216, Center for Global Development, Washington, DC.

Llavador, H. G. and J. E. Roemer (2001), 'An equal-opportunity approach to the allocation of international aid', Journal of Development Economics, 64: 147-171.

McGillivray, M. (2004), 'Descriptive and prescriptive analyses of aid allocation: approaches, issues, and consequences', International Review of Economics and Finance, 13: 275-292.

McIntyre, D., F. Meheus and J.-A. Røttingen (2017), 'What level of domestic government health expenditure should we aspire to for universal health coverage?', Health Economics, Policy and Law, 12(2): 125-137.

Moon, S. and O. Omole (2013), 'Development Assistance for Health: Critiques and Proposals for Change', Centre on Global Health Security Working Group Papers, Chatham House, London.

Neumayer, E. (2003), 'The determinants of aid allocation by regional multilateral development banks and United Nations agencies', International Studies Quarterly, 47(1): 101-122.

Ooms, G., K. Derderian and D. Melody (2006), 'Do we need a world health insurance to realise the right to health?', PLoS Medicine, 3(12): e530.

Ottersen, T., A. Kamath, S. Moon, L. Martinsen and J.-A. Røttingen (2017), 'Development assistance for health: what criteria do multi- and bilateral funders use', Health Economics, Policy and Law, 12(2): 223-244.

Ottersen, T., S. Moon and J.-A. Røttingen (2017), 'The challenge of middle-income countries to development assistance for health: recipients, funders, both or neither', Health Economics, Policy and Law, 12(2): 265-284.

Pietschmann, E. (2014), Forgotten or Unpromising? The Elusive Phenomenon of Under-Aided Countries, Sectors and Sub-National Regions, Bonn: German Development Institute.

Resch, S., T. Ryckman and R. Hecht (2015), 'Funding AIDS programmes in the era of shared responsibility: an analysis of domestic spending in 12 low-income and middle-income countries', Lancet Global Health, 3: e52-e61. 
Røttingen, J.-A., T. Ottersen, A. Ablo, D. Arhin-Tenkorang, C. Benn, R. Elovainio, D. B. Evans, L. E. Fonseca, J. Frenk, D. McCoy, D. McIntyre, S. Moon, G. Ooms, T. Palu, S. Rao, D. Sridhar, J. Vega, S. Wibulpolprasert, S. Wright and B. M. Yang. (2014), 'Shared Responsibilities for Health: A Coherent Global Framework for Health Financing', London: Chatham House.

Salois, M. J. (2012), 'Biases in the distribution of bilateral aid: a regional decomposition analysis', Applied Economics Letters, 19(2): 203-206.

Salvado, R. C. and J. Walz (2013), 'Aid Eligibility and Income Per Capita: A Sudden Stop for MICs?', DPAF Working Paper Series, Bill \& Melinda Gates Foundation, Seattle.

Stuckler, D., S. Basu, S. W. Wang and M. McKee (2011), 'Does recession reduce global health aid? Evidence from 15 high-income countries, 1975-2007', Bulletin of the World Health Organization, 89: 252-257.

Sumner, A. (2012), 'Where do the poor live?', World Development, 40(5): 865-877.

Thomas, A. (2013), Do Middle-Income Countries Need Aid? Literature Review and Analysis of Evidence and Opinions Used in the Aid Differentiation Debate, London: Bond.

Vázquez, S. T. (2015), 'Geographical Allocation of Aid: Lessons from Political Economy', in B. M. Arvin and B. Lew (eds) Handbook of the Economics of Foreign Aid, Cheltenham: Edward Elgar Publishing.

Word Bank (2015), 'Country and lending groups', http://data.worldbank.org/about/countryand-lending-groups [2 March 2015]. 